\title{
Intraperitoneal Bladder Injury - A Conservative Approach
}

\author{
Senthil Kumar Thiagarajan ${ }^{1}$, Gaddam Shashidhar Reddy², K.S.N.S. Udbhav³ \\ Srinivasan Thimmaraju ${ }^{4}$, Saravanan Jambunathan ${ }^{5}$
}

1, 2, 3, 4, 5 Department of Urology, SRM Medical College Hospital, Potheri, Tamil Nadu, India.

\section{INTRODUCTION}

Iatrogenic bladder injuries with Intra-peritoneal extravasations are standardly managed surgically. However, we are presenting a case of iatrogenic intra-peritoneal bladder injury which developed after an emergency caesarean section that was managed successfully by conservative therapy. The trial of conservative approach may prove beneficial to minimize the chances of any invasive interventions in such cases.

Bladder injuries are of two types namely intra-peritoneal and extra-peritoneal. Of which, extra-peritoneal is most common type. ${ }^{1}$ Bladder laceration happens during separation of bladder from uterine cervix during caesarean sections and abdominal hysterectomies. ${ }^{2}$ Usually bladder injuries are identified intra-operatively and managed on table. If diagnosis is made post-operatively, then management becomes challenging due to non-specific clinical features, exposure to radiation, sepsis due to urinary extravasation and prolonged hospital stay, psychological stress to both patient and surgeon.

The clinical features suspicious of bladder injury are abdomen distension, urinary ascites, blood-stained urine, abdominal pain, paralytic ileus, fever and deranged renal parameters. ${ }^{3}$ Extra-peritoneal and intra-peritoneal bladder ruptures are treated differently. According to American Urological Association (AUA) guidelines, Intraperitoneal bladder injury needs surgical repair. There are limited case reports in literature about conservative management of small intra-peritoneal bladder lacerations. This is a case report of one such intra-peritoneal bladder injury treated with non-operative approach.

\section{PRESENTATION OF CASE}

A 30-year-old female with G2P1L1 underwent emergency lower segment caesarean section (LSCS) due to obstructed labour. On post-operative day-2, patient developed paralytic ileus with abdominal bloating and oliguria. She was kept on nil per oral and Ryle's tube was introduced. Abdominal girth chart was measured and showed increase in girth.

Investigations proceeded with complete hemogram, renal function test, with serum creatinine as $5 \mathrm{mg} / \mathrm{dl}$ with leukocytosis. Ultrasound of abdomen showed intraperitoneal collection. CT cystogram was done (figure-1, 2) which showed contrast extravasation into peritoneal cavity with bladder injury at dome approximate $6 \mathrm{~mm}$ in size. Treatment options are discussed with patient regarding conservative management and need for bladder repair if condition worsens. Patient was planned for catheterization and trial conservative management. After 2 days of catheterization, patient had improvement of symptoms - Urine output was measured which showed $1600 \mathrm{ml}$, serum creatinine was $2 \mathrm{mg} / \mathrm{dl}$. Post 3 days after catheterization, patient was allowed orally after 3 days she was tolerating orals , subsequently she was maintaining adequate urine output. Serum creatinine was 1 $\mathrm{mg} / \mathrm{dl} 5$ days post catheterization Follow-up computed tomography (CT) cystogram was done after 10 days of catheterization which showed no evidence of contrast leak into peritoneum (figure-3). Catheter was removed on $14^{\text {th }}$ day post catheterisation day. Patient passed urine normally and followed up for next 3 months and was uneventful.
Corresponding Author: Dr. Gaddam Shashidhar Reddy, SRM Institute of Science and Technology, Potheri Kattankulathur - 603203, Chengalpattu District, Tamil Nadu, India. E-mail:Shashimrmc2@gmail.com

DOI: $10.14260 / \mathrm{jemds} / 2021 / 697$

How to Cite This Article: Thiagarajan SK, Reddy GS, Udbhav KSNS, et al. Intraperitoneal bladder injury - A conservative approach. J Evolution Med Dent Sci 2021;10(38):3446-3448, DOI: $10.14260 /$ jemds/2021/697

Submission 12-07-2021,

Peer Review 26-08-2021,

Acceptance 03-09-2021,

Published 20-09-2021.

Copyright (c) 2021 Senthil Kumar Thiagarajan et al. This is an open access article distributed under Creative Commons Attribution License [Attribution 4.0 International (CC BY 4.0)] 


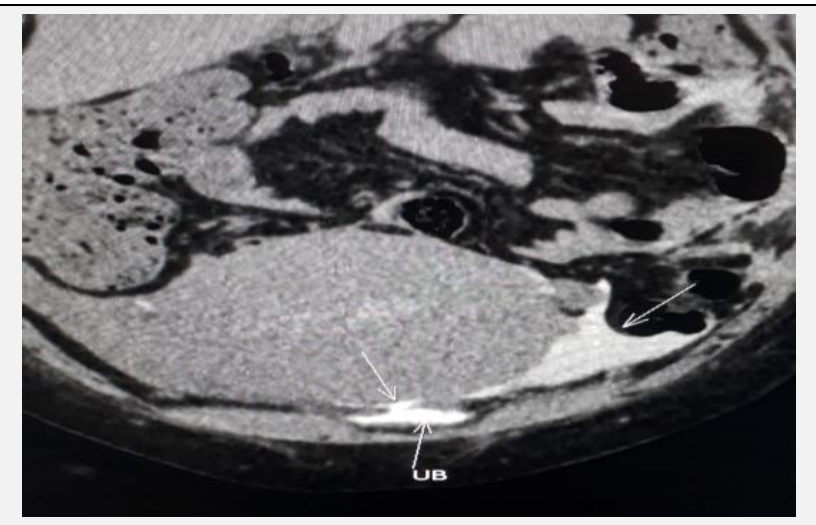

Figure 1. CT Cystogram Showing Intra-Peritoneal Contrast Extravasation
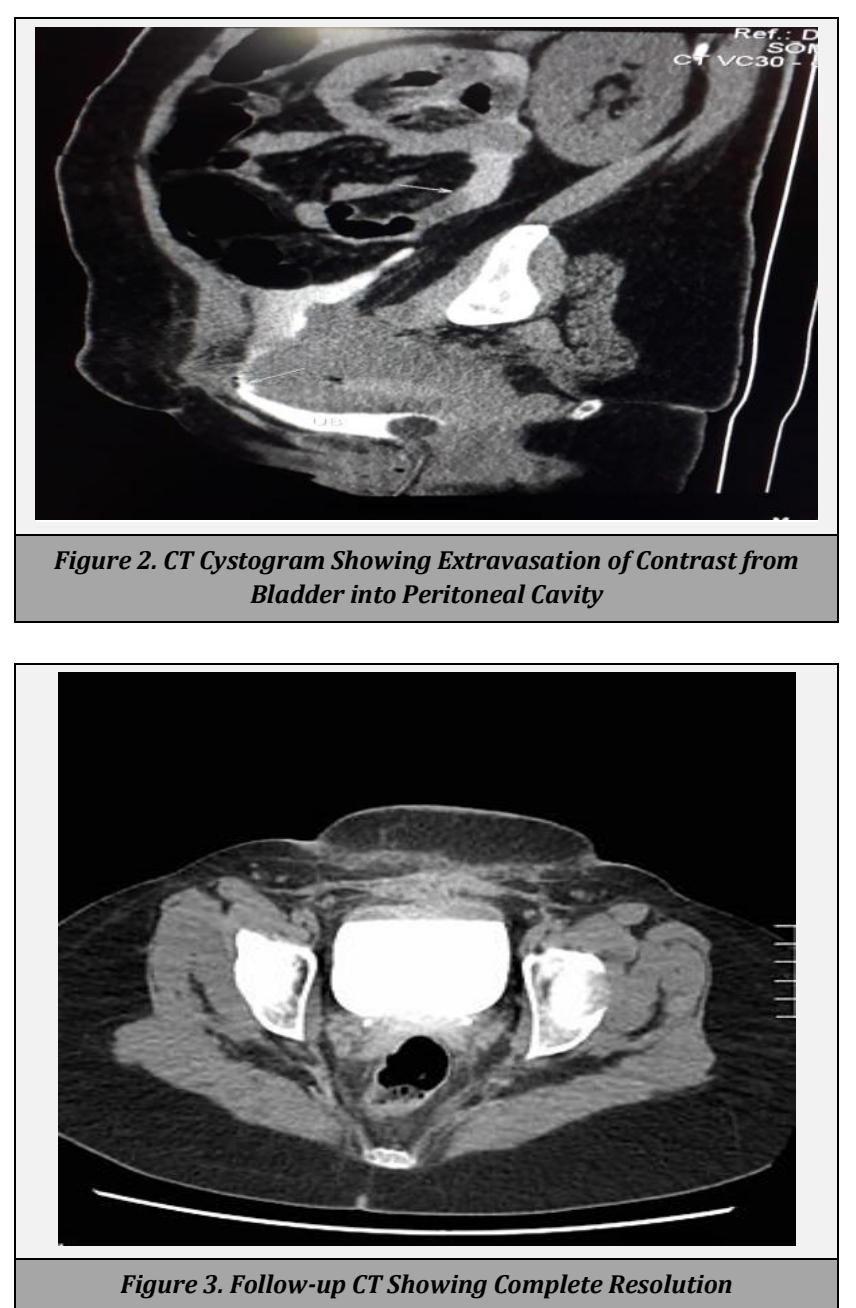

\section{CLINICAL DIAGNOSIS}

Intra-peritoneal bladder injury with elevated renal parameters

\section{DIFFERENTIAL DIAGNOSIS}

1. Ureteric injuries with intra-peritoneal urine extravasation.

2. Intestinal injury with faecal peritonitis.

3. Foreign body in peritoneal cavity.

\section{DISCUSSION}

Bladder injuries commonly occur during caesarean section, not uncommon during hysterectomy. Proximity of dome of bladder to uterine cervix and dense adhesions that is formed during previous caesarean sections predispose to injuries at dome of bladder during repeat caesarean section. Early detection of bladder injuries is possible with high suspicion on table intra-operatively gush of urine in field, sudden increase in bleeding from the wound foley's bulb is seen and there is visible distortion of bladder integrity. ${ }^{4}$ In case of doubtful bladder injuries, methylene blue instillations intravesical will demonstrate small bladder wall injuries and could be repaired on table. Post operatively, patients with intra-peritoneal bladder injuries have varied presentations varying from mild abdomen fullness and oliguria to peritonitis and sepsis. Investigation of choice is CT cystogram which can demonstrate minute bladder injuries intra-peritoneally and extra peritoneally. CT cystogram should be done cautiously due to chances of introducing infection into peritoneum, aggravation of renal failure and increasing laceration size. Thus, gravity fill method is used for cystogram in filling the bladder. Extra peritoneal bladder injuries can be managed with long term catheterisation. Intra-peritoneal bladder injuries are managed by early surgical intervention and repair of bladder injuries by open or laparoscopic method due to risk of acute renal failure and sepsis.

AUA guidelines strongly recommend for surgical repair of intra-peritoneal lacerations. ${ }^{5,6}$

Bladder injury can be diagnosed by various imaging methods. Sonographic scans detect collection in the pelvis ${ }^{7}$ which could be urine, peritoneal fluid or blood. Plain CT scans cannot differentiate between different fluids and need contrast studies to confirm the diagnosis. ${ }^{8}$ CT cystography with intravenous urogram (IVU) reconstruction is method of choice for the diagnosis of bladder injury. 9,10

Major limitation of CT cystography is radiation exposure with loss of valuable time in unstable patients and in patients with frank peritonitis features who need emergency laparotomy; but in patients with equivocal abdomen signs and doubtful diagnosis, CT cystography plays a vital role in diagnosing and grading of bladder injury and also categorising into intra-peritoneal and extra-peritoneal injuries. Postoperative catheter care is mainly done to prevent catheter block and ensure adequate urine drainage through suprapubic catheter and urethral foley's catheter.

In patients undergoing conservative management for small bladder lacerations, anticholinergic drugs may be indicated in patients with peri catheter leak. Serial measurement of abdominal girth, total leukocyte count, serum urea, serum creatinine and serum electrolytes should be done to assess the recovery of patient. If any signs of sepsis happen like fever, abdominal guarding and altered blood parameters, surgical exploration should be done immediately by either minimal invasive method or open method. Catheter care is essential in cases undergoing genitourinary reconstruction surgeries. ${ }^{11}$ Use of antibiotics can decrease the incidence of urinary tract infections (UTIs) with a urinary catheter. With necessary precautions like nursing, education like proper bladder bag placement and twice-daily perineal care, acquired urinary tract infections can be reduced. ${ }^{12}$ 


\section{CONCLUSIONS}

High level of suspicion of intra-peritoneal bladder injury is required in patients undergoing caesarean section postoperative abdomen distension. Conservative management of intra-peritoneal bladder injury is an option in stable patients with small bladder laceration. Careful selection of patients with close follow-up radiologically and biochemically plays a crucial role in successful outcome. Catheter care, low dose antibiotics and bladder relaxants during healing phase augments the outcome. Since reported number of patients managed conservatively is very less in literature, this case report might encourage conservative management in selected number of patients.

Financial or other competing interests: None.

Disclosure forms provided by the authors are available with the full text of this article at jemds.com.

\section{REFERENCES}

[1] Wein AJ, Kavoussi LR, Partin AW, et al. Campbell-Walsh Urology. 11 th edn. Philadelphia, PA: Elsevier Saunders 2016.

[2] Phipps MG, Watabe B, Clemons JL, et al. Risk factors for bladder injury during cesarean delivery. Obstet Gynecol 2005;105(1):156-60.

[3] Gomez RG, Ceballos L, Coburn M, et al. Consensus statement on bladder injuries. BJU International 2004;94(1):27-32.
[4] Rahman MS, Gasem T, Al Suleiman SA, et al. Bladder injuries during cesarean section in a university hospital a 25 year review. Arch Gynecol Obstet 2009;279(3):34952.

[5] Phillips B, Holzmer S, Turco L, et al. Trauma to the bladder and ureter: a review of diagnosis, management and prognosis. Eur J Trauma Emerg Surg 2017;43(6):763-73.

[6] Morey AF, Brandes S, Dugi DD 3rd, et al. Urotrauma: AUA guideline. J Urol 2014;192(2):327-35.

[7] Bain K, Kassapidis V, Meytes V, et al. FAST examination diagnosing bladder rupture following blunt pelvic trauma. BMJ Case Rep 2018;2018:bcr2017223933.

[8] Landman W, Khurana B, Briggs A, et al. BWH emergency radiology-surgical correlation: intraperitoneal urinary bladder rupture. Emerg Radiol 2015;22(6):713-6.

[9] Vaccaro JP, Brody JM. CT cystography in the evaluation of major bladder trauma. Radiographics 2000;20(5):137381.

[10] Quagliano PV, Delair SM, Malhotra AK. Diagnosis of blunt bladder injury: a prospective comparative study of computed tomography cystography and conventional retrograde cystography. J Trauma 2006;61(2):410-21.

[11] Shaver B, Eyerly-Webb SA, Gibney Z, et al. Trauma and intensive care nursing knowledge and attitude of Foley catheter insertion and maintenance. J Trauma Nurs 2018;25(1):66-72.

[12] Elkbuli A, Miller A, Boneva D, et al. Targeting catheterassociated urinary tract infections in a trauma population: a 5-S bundle preventive approach. J Trauma Nurs 2018;25(6):366-73. 